\title{
Computed tomography-generated anthropometric measurements of orbital relationships in normal infants and children
}

\author{
Garrett M. Pool, MD, ${ }^{1}$ Ryne A. Didier, MD, ${ }^{2}$ Dianna Bardo, MD, ${ }^{2}$ Nathan R. Selden, MD, $\mathrm{PhD},{ }^{3}$ and \\ Anna A. Kuang, MD ${ }^{4}$ \\ ${ }^{1}$ General Surgery, Bassett Medical Center, Cooperstown, New York; and Departments of ${ }^{2}$ Radiology, ${ }^{3}$ Neurological Surgery, and \\ ${ }^{4}$ Division of Pediatric Surgery, Department of Surgery, Oregon Health \& Science University, Portland, Oregon
}

OBJECTIVE The aim of this study was to develop soft-tissue and bony anthropometric orbital measurements in a normal pediatric population based upon CT scans.

METHODS This was a retrospective stratified study of children with ages ranging from birth to 36 months. Head CT images for 204 children were available and obtained with 0.625-1-mm slice widths. Soft-tissue and bone windows were reviewed. Images were oriented in the Frankfort horizontal plane, and the intercanthal (IC), bony interorbital (IO), and bony lateral orbital (LO) distances were measured. Age group stratifications were $0-3,>3-6,>6-9,>9-12,>12-18$, $>18-24,>24-30$, and $>30-36$ months. Patients with known syndromes or craniofacial abnormalities were excluded. Statistical analysis included the mean, SD, SEM, $95 \% \mathrm{Cl}$, and an evaluation of IO:LO ratio.

RESULTS There was an average of 25.5 patients in each age group (range 25-27 patients). All soft-tissue and bony measurements consistently showed rapid increase from 0 -6 months of age, which tapered after age $>12$ months. The mean IC, bony IO, and bony LO distances started at $22.22 \pm 1.13 \mathrm{~mm}, 14.16 \pm 0.74 \mathrm{~mm}$, and $65.56 \pm 1.76 \mathrm{~mm}$, and at 12 months were $27.74 \pm 1.01 \mathrm{~mm}, 16.21 \pm 0.75 \mathrm{~mm}$, and $77.98 \pm 1.57 \mathrm{~mm}$, respectively. The bony LO position was equivalent to the lateral canthal position and measurements. The IC distance was approximately one-third the lateral canthal distance for all age groups.

CONCLUSIONS This study established and reported normal anthropometric orbital measurements in a pediatric population using fine-cut craniofacial CT. These measurements are essential when evaluating children with craniofacial anomalies.

http://thejns.org/doi/abs/10.3171/2016.2.PEDS15475

KEY WORDS orbital measurements; normal; pediatric; $\mathrm{CT}$; computed tomography; craniofacial

$\Lambda$ NTHROPOMETRIC measurements are a well-established method of craniofacial evaluation. ${ }^{4,9,13}$, 15-21,23-25,27,30,36 Since the Renaissance, professionals have been interested in describing and recording measurements of the human face. These pioneers included artists and scholars such as da Vinci, Bergmüller, Dürer, and Elsholtz, who described the facial proportions used by artists for centuries, including the neoclassical canon of facial fifths. ${ }^{3,8,10,11}$ This centuries-old acceptable proportion of beauty divides the face vertically into fifths, with the width of each eye, the intercanthal distance, and the nasal width all measuring one-fifth. ${ }^{32}$ In 1843, Swedish anatomist Anders Retzius introduced the cephalic index, as Farkas et al. have previously described. ${ }^{12-20}$ Since that time, external anthropometric measurements, indices, and proportions have been extensively expanded,,$^{14}$ serving the medical community as a consistently accurate and reproducible method for comparison of normal facial characteristics across multiple ethnicities. . $^{2,413-15,17,21,25,31,33,36}$

Existing data have been generated by direct measurement (anthropometrics) and/or radiographic measurement (cephalometrics) of orbital anatomical characteristics and have more recently included ultrasound measurements of fetuses in utero. ${ }^{34}$ Anthropometric measurements have generated a large database of normal values based on surface measurements, in which relatively thin soft tissues overlie bony surfaces, allowing for accurate measurement without the use of ionizing radiation..$^{20}$ Anthropometric measurements, however, are subject to inter- and intraobserver variability, require frequent performance to main-

ABBREVIATIONS $I C=$ intercanthal; $I O=$ interorbital; $L O=$ lateral orbital.

SUBMITTED August 5, 2015. ACCEPTED February 11, 2016.

INCLUDE WHEN CITING Published online April 29, 2016; DOI: 10.3171/2016.2.PEDS15475. 


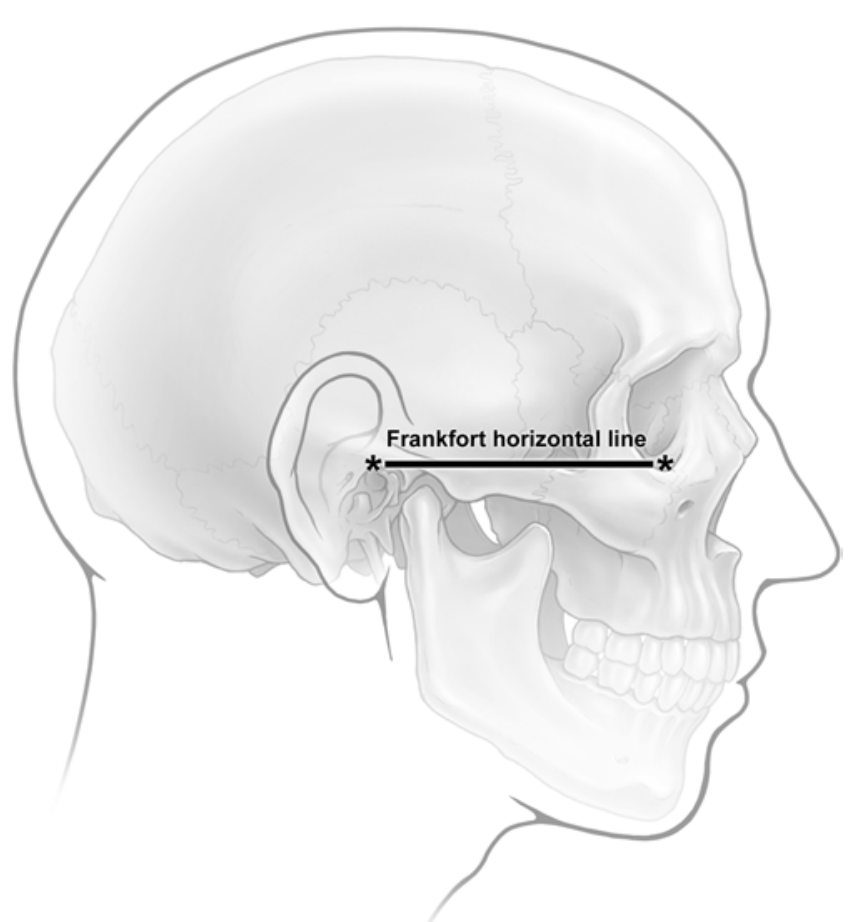

FIG. 1. Artist's representation of the Frankfort horizontal plane (asterisks mark the highest point on the upper margin of each external auditory canal and the low point on the inferior margin of the left orbit). Copyright Oregon Health \& Science University. Published with permission.

tain the skill necessary to make accurate comparisons, ${ }^{12,14}$ and involve difficulties with cooperation by infants and children, some of whom have genetic syndromes and/or developmental limitations. ${ }^{12,16}$ Cephalometric measurements require less patient cooperation but use ionizing radiation $^{36}$ and involve nonstandardized magnification factors, which can lead to uneven landmark positioning. ${ }^{22}$ Ultrasound measurements are a safe and convenient modality for assessing prenatal anomalies, but ultrasound is not feasible postpartum.

The largest proportion of anthropometric data applies to adults ${ }^{4,9,17,18,22-25,30,31,36}$ and to a lesser extent to the pediatric population. ${ }^{9} 13,16,18,19,21,27,30,36$ There are relatively few data available for children younger than 3 years., ${ }^{9,16,21,24,27}$ For example, Farkas and Posnick evaluated subjects as young as 1 year, but omitted data from birth to 1 year due to a small sample size and uncooperative patients. ${ }^{19}$ Pediatric specialists and primary care providers perform evaluations of the craniofacial skeleton when their patients are very young and typically at $<1$ year of age. Normative data in this age group would be helpful in the diagnosis and assessment of craniofacial anomalies, as well as surgical planning. $15,17,20,31,36$

Computed tomography imaging is extensively used in evaluating craniofacial and brain anatomy in adults and children. Combined with its widespread availability, CT imaging thus becomes an ideal technique for developing a database of normal measurements. There are limited data available regarding orbital soft-tissue and bony relationships in the pediatric population. Therefore, this study

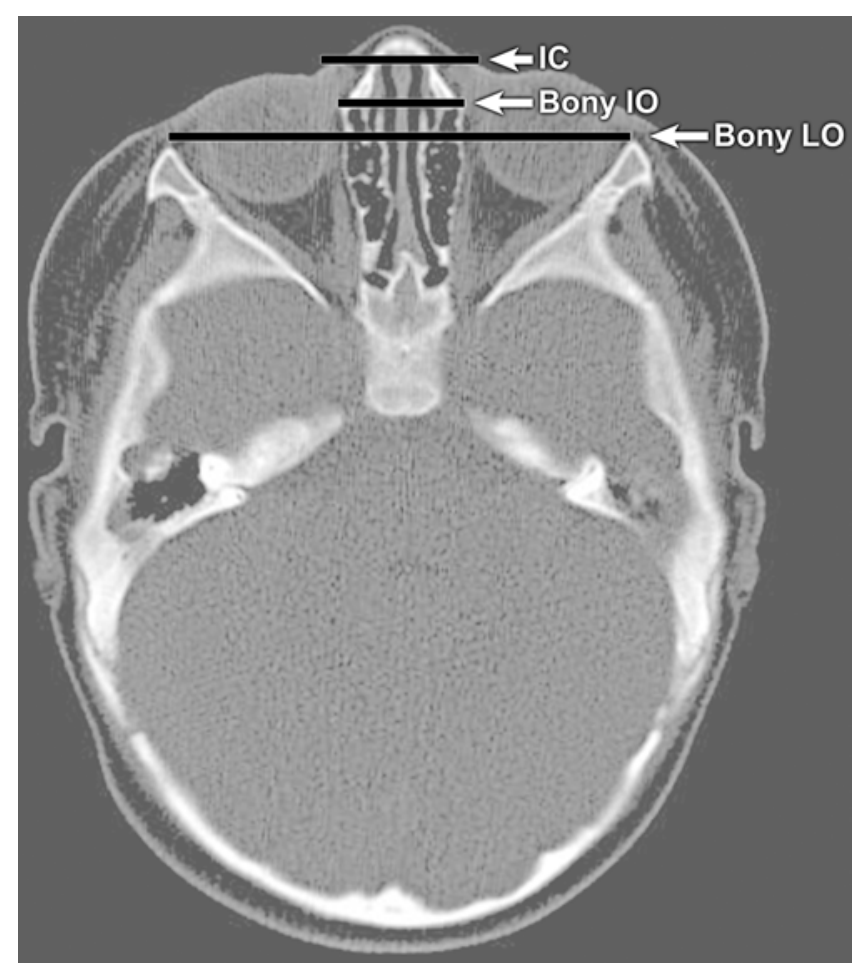

FIG. 2. Axial CT scan showing distances measured: IC, bony IO, and bony LO.

used retrospective review of CT images obtained for other indications in normal children to establish soft-tissue and bony anthropometric orbital measurements, which may be used to guide evaluation and surgical recommendations in children with craniofacial abnormalities.

\section{Methods}

This study was approved by the Oregon Health \& Science University institutional review board, and a waiver of informed consent was granted. Clinically indicated head CT imaging performed on children from birth to 36 months of age, obtained between November 2008 and July 2013, was retrospectively reviewed. We used fine-cut head/maxillofacial CT scans that had been obtained to evaluate positional plagiocephaly and polytrauma. Based on chart review and evaluation of the scan, we excluded any patient with prior or impending surgery, craniofacial syndromes, or known syndromic diagnoses. Two hundred four children were included in the final analysis. The number of patients included for each age group ranged

TABLE 1. Age at CT and mean craniofacial distance measurements for 204 patients

\begin{tabular}{crcccc}
\hline Parameter & $\begin{array}{c}\text { Age at CT } \\
(\mathrm{mos})\end{array}$ & IC $(\mathrm{mm})$ & $\begin{array}{c}\text { Bony IO } \\
(\mathrm{mm})\end{array}$ & $\begin{array}{c}\text { Bony LO } \\
(\mathrm{mm})\end{array}$ & IO:LO \\
\hline Min & 0.00 & 16.40 & 9.80 & 53.70 & 0.16 \\
\hline Max & 35.56 & 35.30 & 29.00 & 88.00 & 0.34 \\
\hline
\end{tabular}

Max $=$ maximum $;$ min $=$ minimum 
TABLE 2. Interorbital measurements of 204 patients by age group

\begin{tabular}{|c|c|c|c|c|c|c|c|}
\hline \multirow{2}{*}{$\begin{array}{c}\text { Age Group, } \\
\text { Mos }\end{array}$} & \multirow[b]{2}{*}{ Sex, M/F } & \multirow{2}{*}{$\begin{array}{c}\text { Mean Age at } \\
\text { CT, Mos }\end{array}$} & \multicolumn{4}{|c|}{ Value, $\mathrm{mm} \pm 95 \% \mathrm{Cl}$} & \multirow[b]{2}{*}{ IC:Bony LO } \\
\hline & & & Mean IC & Mean Bony 10 & Mean Bony LO & IO:LO & \\
\hline $0-3$ & $17: 8$ & 1.65 & $22.22 \pm 1.13$ & $14.16 \pm 0.74$ & $65.56 \pm 1.76$ & $0.22 \pm 0.009$ & 0.34 \\
\hline$>3-6$ & $16: 9$ & 4.24 & $24.65 \pm 0.83$ & $15.50 \pm 0.48$ & $71.91 \pm 1.46$ & $0.22 \pm 0.004$ & 0.34 \\
\hline$>6-9$ & $18: 7$ & 7.34 & $26.37 \pm 0.87$ & $15.20 \pm 0.65$ & $74.63 \pm 1.34$ & $0.20 \pm 0.008$ & 0.35 \\
\hline$>9-12$ & $13: 12$ & 10.27 & $26.24 \pm 1.09$ & $15.52 \pm 0.69$ & $75.66 \pm 1.51$ & $0.20 \pm 0.008$ & 0.35 \\
\hline$>12-18$ & $16: 10$ & 13.83 & $27.74 \pm 1.01$ & $16.21 \pm 0.75$ & $77.98 \pm 1.57$ & $0.21 \pm 0.007$ & 0.36 \\
\hline$>18-24$ & $16: 11$ & 20.81 & $28.01 \pm 0.97$ & $15.67 \pm 0.70$ & $78.90 \pm 1.30$ & $0.20 \pm 0.007$ & 0.36 \\
\hline$>24-30$ & $14: 12$ & 26.30 & $28.05 \pm 0.74$ & $16.02 \pm 0.60$ & $80.44 \pm 0.62$ & $0.20 \pm 0.007$ & 0.35 \\
\hline$>30-36$ & $17: 8$ & 32.33 & $28.46 \pm 1.12$ & $16.75 \pm 1.23$ & $80.55 \pm 1.07$ & $0.21 \pm 0.01$ & 0.35 \\
\hline Total & $127: 77$ & & & & & & \\
\hline
\end{tabular}

from 25 to 27 . Overall, there were 127 boys (62\%) and 77 girls $(38 \%)$.

All images were obtained with 0.625 - to 1 -mm slices, and soft tissue and bone windows were reviewed. The key points of measurement were determined by the craniofacial surgeon and the lead radiologist. Interrater reliability was determined to be $90 \%$. The lead author (G.M.P.) performed all measurements to minimize rater error in data collection.

Orientation was in the Frankfort horizontal plane (the highest point on the upper margin of the opening of each external auditory canal and the low point on the lower margin of the left orbit; Fig. 1). Image manipulation and measurements were made using an Extended Brilliance Workspace (Philips). The skull was first leveled in the transverse plane, using the cochlea as a reference point to adjust left and right into the same image. In the sagittal plane, the head was then aligned using the most superior point of the left external auditory canal and the most inferior point of the left orbit to establish the Frankfort horizontal plane. From here, we advanced the transverse slices superiorly to the medial canthus and proceeded to use the workstation linear measurement tool to obtain measurements of the soft-tissue intercanthal (IC), bony interorbital (IO), and bony lateral orbital (LO) distances (Fig. 2).

Because of rapid growth of the skull and periorbital region during the 1st year of life, patients were stratified into the following age groups (in months): $0-3,>3-6,>6-9,>$ 9-12, > 12-18, > 18-24, > 24-30, and > 30-36. Statistical analysis included calculation of the IO to LO ratio, mean, SD, SEM, and 95\% CI.

\section{Results}

Aggregate IC, IO, and LO distance ranges are shown in Table 1, as well as the IO:LO ranges. In the stratified groups, boys and girls were analyzed together because several studies have indicated that distance differences between male and female patients are not statistically significant in the included age groups. $23,27,29,36$ The mean measurements for each age group are depicted in Table 2.

The mean IC distance in the 0 - to 3 -month age group was $22.22 \pm 1.13 \mathrm{~mm}$, with a steady increase up to the $>$
TABLE 3. Values for mean, SD, SEM, and $95 \% \mathrm{Cl}$ by age group for orbital distances

\begin{tabular}{|c|c|c|c|c|c|}
\hline $\begin{array}{c}\text { Age Group, } \\
\text { mos }\end{array}$ & Parameter & IC & $\begin{array}{l}\text { Bony } \\
10\end{array}$ & $\begin{array}{l}\text { Bony } \\
\text { LO }\end{array}$ & IO:LO \\
\hline \multirow[t]{4}{*}{$0-3, n=25$} & Mean & 22.22 & 14.16 & 65.56 & 0.22 \\
\hline & SD & 2.8717 & 1.8881 & 4.4877 & 0.0216 \\
\hline & SEM & 0.5743 & 0.3776 & 0.8975 & 0.0085 \\
\hline & $95 \% \mathrm{Cl}$ & 1.1257 & 0.7401 & 1.7591 & 0.0085 \\
\hline \multirow[t]{4}{*}{$>3-6, n=25$} & Mean & 24.65 & 15.50 & 71.91 & 0.22 \\
\hline & SD & 2.1245 & 1.2366 & 3.7340 & 0.0112 \\
\hline & SEM & 0.4249 & 0.2473 & 0.7468 & 0.0022 \\
\hline & $95 \% \mathrm{Cl}$ & 0.8328 & 0.4847 & 1.4637 & 0.0044 \\
\hline \multirow[t]{4}{*}{$>6-9, n=25$} & Mean & 26.37 & 15.20 & 74.63 & 0.20 \\
\hline & SD & 2.2235 & 1.6530 & 3.4261 & 0.0197 \\
\hline & SEM & 0.8328 & 0.4847 & 1.4637 & 0.0044 \\
\hline & $95 \% \mathrm{Cl}$ & 0.8716 & 0.6480 & 1.3430 & 0.0077 \\
\hline \multirow[t]{4}{*}{$>9-12, n=25$} & Mean & 26.24 & 15.52 & 75.66 & 0.20 \\
\hline & SD & 2.7687 & 1.7642 & 3.8530 & 0.0193 \\
\hline & SEM & 0.5537 & 0.3528 & 0.7706 & 0.0039 \\
\hline & $95 \% \mathrm{Cl}$ & 1.0853 & 0.6915 & 1.5104 & 0.0076 \\
\hline \multirow[t]{4}{*}{$>12-18, n=26$} & Mean & 27.74 & 16.21 & 77.98 & 0.21 \\
\hline & SD & 2.6257 & 1.9563 & 4.0824 & 0.0193 \\
\hline & SEM & 0.5149 & 0.3837 & 0.8006 & 0.0038 \\
\hline & $95 \% \mathrm{Cl}$ & 1.0093 & 0.7520 & 1.5692 & 0.0074 \\
\hline \multirow[t]{4}{*}{$>18-24, n=27$} & Mean & 28.01 & 15.67 & 78.90 & 0.20 \\
\hline & SD & 2.5608 & 1.8558 & 3.4382 & 0.0183 \\
\hline & SEM & 0.4928 & 0.3571 & 0.6617 & 0.0035 \\
\hline & $95 \% \mathrm{Cl}$ & 0.9659 & 0.7000 & 1.2969 & 0.0069 \\
\hline \multirow[t]{4}{*}{$>24-30, n=26$} & Mean & 28.05 & 16.02 & 80.44 & 0.20 \\
\hline & SD & 1.9182 & 1.5613 & 3.1452 & 0.0170 \\
\hline & SEM & 0.9659 & 0.7000 & 1.2969 & 0.0069 \\
\hline & $95 \% \mathrm{Cl}$ & 0.7373 & 0.6001 & 1.2089 & 0.0066 \\
\hline \multirow[t]{4}{*}{$>30-36, n=25$} & Mean & 28.46 & 16.75 & 80.55 & 0.21 \\
\hline & SD & 2.8531 & 3.1265 & 2.7169 & 0.0347 \\
\hline & SEM & 0.5706 & 0.6253 & 0.5434 & 0.0069 \\
\hline & $95 \% \mathrm{Cl}$ & 1.1184 & 1.2256 & 1.0650 & 0.0136 \\
\hline
\end{tabular}



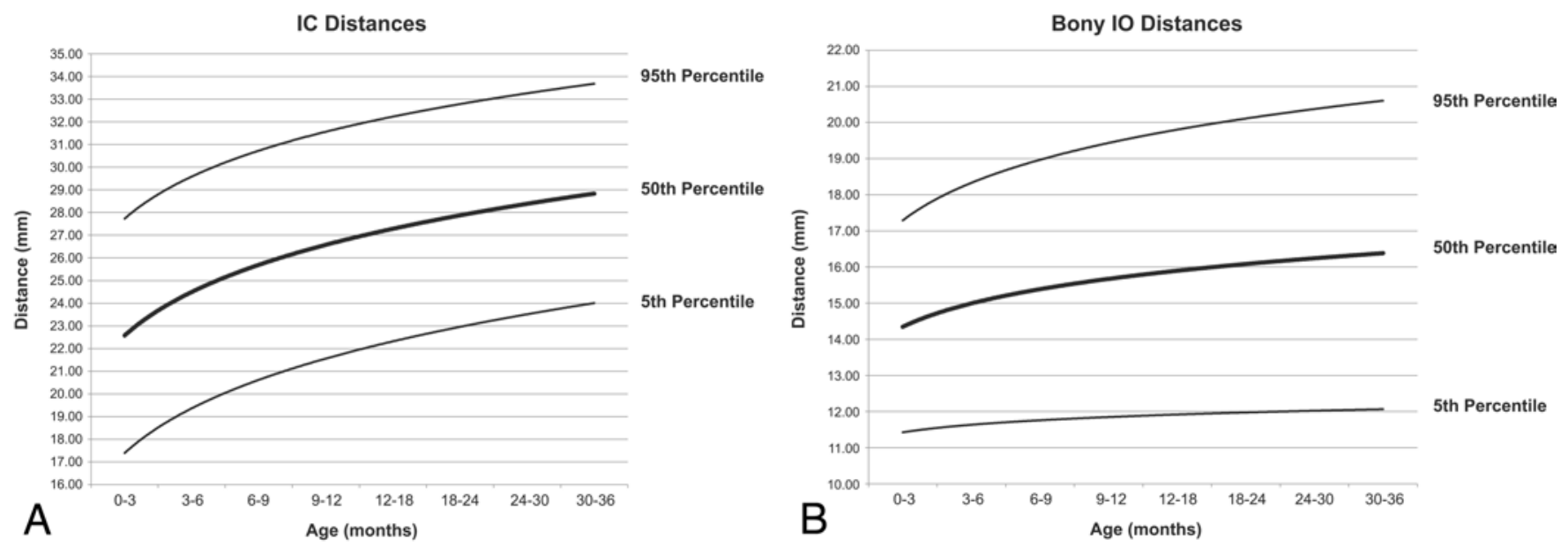

Bony LO Distance

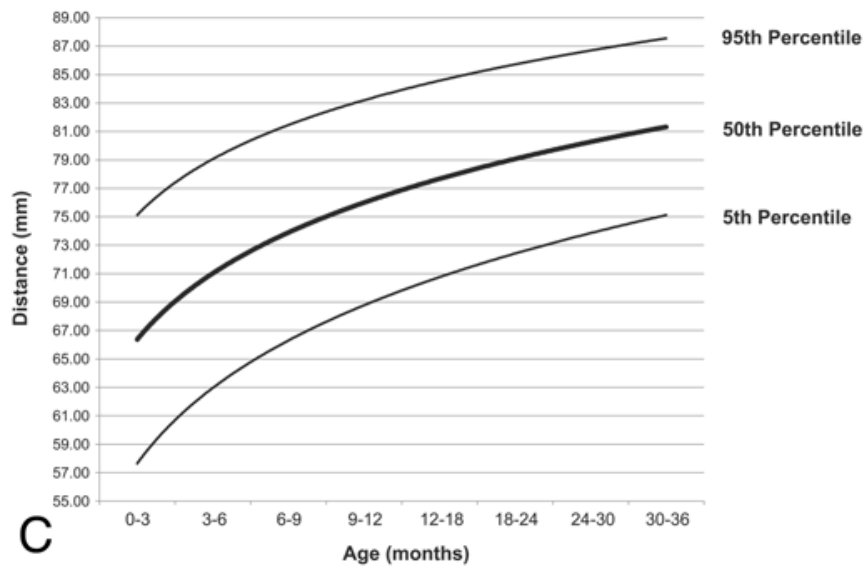

FIG. 3. Normal cranial growth charts depicting IC (A), bony IO (B), and bony LO (C) distances.

12- to 18-month-old group (mean $27.74 \pm 1.01 \mathrm{~mm}$ ). After 18 months of age, the mean IC distance was relatively stable, averaging $28-28.5 \mathrm{~mm}$.

The mean bony IO distance in the 0 - to 3-month-old group was $14.16 \pm 0.74 \mathrm{~mm}$, with a steady increase to $16.21 \pm 0.75 \mathrm{~mm}$ in the $>12$ - to 18 -month-old group. After 18 months of age, the mean bony IO distance was stable, averaging $15.7-16.8 \mathrm{~mm}$.

The mean bony LO (lateral canthal) distance in the 0 - to 3-month age group was $65.56 \pm 1.76 \mathrm{~mm}$ and increased to $77.98 \pm 1.57 \mathrm{~mm}$ at age $>12$ - to 18 -month-old group, and rose gradually from 79 to $80.5 \mathrm{~mm}$ at $>18$ - to 36-month-old group.

To analyze a possible role in overall facial width with respect to IO distance, we looked at the ratio of the IO to the LO distance. The mean IO:LO ratio was generally consistent across age groups, with a trend toward larger ratios in the 0- to 3-month-old and the $>3$ - to 6-month-old groups and smaller ratios in the older age groups. However, the margin of error was too small to find significant differences in IO:LO ratio between the age groups.

We also compared our measured distances with facial fifths proportions and found that measurements were comparable and consistent with these accepted facial pro- portions, in that the IC distance was approximately onethird (0.33) the distance at the bony $\mathrm{LO}$ (the LO position is equivalent to the lateral canthal distance) (Table 2).

There was an average of 25.5 patients in each group (range 25-27 patients). Detailed results for the mean, SD, SEM, and $95 \%$ CI by age group are depicted in Table 3 .

\section{Discussion}

Facial measurements and proportions have traditionally been calculated using plain radiographs, primarily in the adult population., ${ }^{1,6,13}$ There is limited availability of pediatric measurements, because of fewer individuals. Over the past 2 decades, CT imaging has provided accurate and reproducible measurements of the craniofacial skeleton in both adult and pediatric populations. , $^{5,26,35}$ We aimed to provide previously unreported normative data for children from birth to 36 months of age. Orbital growth follows a pattern similar to that of cranial growth, with the most rapid expansion during the first 12 months of life., ${ }^{9,16,19-21}$ Anthropometric measurements for this younger population have not been available until now.

We compared the present data with published data obtained using alternate methodologies, including fetal ultrasound and postnatal anthropometric measurements. 
The present data for 0- to 3-month-old children aligned perfectly with data obtained using ultrasound for full-term fetuses. ${ }^{34}$ The present data also closely approximate anthropometric data from birth to 36 months of age., ${ }^{9,21}$

The present measurements also conform to traditional definitions of balanced facial proportion, as determined by the rule of facial fifths, stating that the IC difference should be one-third of the distance between lateral canthal distances. Our normative data analysis result falls within the accepted balanced facial proportions. ${ }^{9,12-15,21,24,28}$ The only variant data for the measurements reported here were obtained using presumably less accurate non-CT methodologies. ${ }^{9,24}$

Using the present CT data, we developed normative cranial growth charts (Fig. 3), which could be used to help evaluate infants and young children with congenital or acquired craniofacial abnormalities. These nomograms were developed for specified age groups based on the means bracketed by 2 SDs (Excel chart creation).

The present study is limited by sample size (approximately 25 patients per 3-month stratified age groups) and failure to control systematically for the influence of ethnicity, which has been reported to influence orbital anthropometrics. ${ }^{2,4,13-15,17,21,25,31,33,36}$ Future studies with larger numbers of patients should also include interobserver reliability measurements, as well as an analysis of measurement training and performance efficiency in comparing CT imaging with traditional anthropomorphic measurements.

\section{Conclusions}

We established normal anthropometric measurements of the orbit in a pediatric population using craniofacial CT imaging. This analysis is especially important in infants, an age group for which current data are limited. Our results provide normative data for evaluating individual patients with craniofacial abnormalities as well as determining the response to surgical reconstruction in individuals or groups. Normal measurements are a useful tool when evaluating the presence of hypo- and hypertelorism in children with craniofacial abnormalities.

\section{Acknowledgments}

We thank Shirley McCartney, PhD, and Andy Rekito, MS, for manuscript processing and figure preparation, respectively.

\section{References}

1. Barkovich A: Pediatric Neuroimaging, ed 2. New York: Raven Press, 1995

2. Barretto RL, Mathog RH: Orbital measurement in black and white populations. Laryngoscope 109:1051-1054, 1999

3. Bergmüller JG: Anthropometria. Augsburg: J. J. Lotter, 1723

4. Borman H, Ozgür F, Gürsu G: Evaluation of soft-tissue morphology of the face in 1,050 young adults. Ann Plast Surg 42:280-288, 1999

5. Carr M, Posnick JC, Pron G, Armstrong D: Cranio-orbitozygomatic measurements from standard CT scans in unoperated Crouzon and Apert infants: comparison with normal controls. Cleft Palate Craniofac J 29:129-136, 1992

6. Chasler C: Atlas of Roentgen Anatomy of the Newborn and Infant Skull. St. Louis: WH Green, 1972
7. Christensen GE, Johnson HJ, Darvann T, Hermann N, Marsh JL: Midsagittal surface measurement of the head: an assessment of craniofacial asymmetry. Proc SPIE 3661:612-619, 1999

8. da Vinci L: I Manoscritti di Leonardo da Vinci della reale biblioteca di Windsor. Dell'Anatomia. Paris: E. Rouveyre, 1898

9. Dekaban AS: Tables of cranial and orbital measurements, cranial volume, and derived indexes in males and females from 7 days to 20 years of age. Ann Neurol 2:485-491, 1977

10. Dürer A: Vier Büicher von menschlicher Proportion. Nuremberg: Hieronymus Formschneyder, 1528

11. Elsholtz JS: Anthropometria: sive de mutua membrorum corporis humani proportione, et Naevorum harmonia libellus. Frankfurt an der Oder: Andreae Becmani, 1663

12. Farkas LG: Accuracy of anthropometric measurements: past, present, and future. Cleft Palate Craniofac J 33:10-22, 1996

13. Farkas LG: Anthropometry of the Head and Face, ed 2. New York: Raven Press, 1994

14. Farkas LG, Deutsch CK: Anthropometric determination of craniofacial morphology. Am J Med Genet 65:1-4, 1996

15. Farkas LG, Hreczko TA, Kolar JC, Munro IR: Vertical and horizontal proportions of the face in young adult North American Caucasians: revision of neoclassical canons. Plast Reconstr Surg 75:328-338, 1985

16. Farkas LG, Hreczko TM, Katic MJ, Forrest CR: Proportion indices in the craniofacial regions of 284 healthy North American white children between 1 and 5 years of age. J Craniofac Surg 14:13-28, 2003

17. Farkas LG, Katic MJ, Forrest CR: Comparison of craniofacial measurements of young adult African-American and North American white males and females. Ann Plast Surg 59:692-698, 2007

18. Farkas LG, Katic MJ, Forrest CR, Alt KW, Bagic I, Baltadjiev G, et al: International anthropometric study of facial morphology in various ethnic groups/races. J Craniofac Surg 16:615-646, 2005

19. Farkas LG, Posnick JC: Growth and development of regional units in the head and face based on anthropometric measurements. Cleft Palate Craniofac J 29:301-302, 1992

20. Farkas LG, Posnick JC, Hreczko TM: Anthropometric growth study of the head. Cleft Palate Craniofac J 29:303308, 1992

21. Farkas LG, Posnick JC, Hreczko TM, Pron GE: Growth patterns in the orbital region: a morphometric study. Cleft Palate Craniofac J 29:315-318, 1992

22. Farkas LG, Tompson BD, Katic MJ, Forrest CR: Differences between direct (anthropometric) and indirect (cephalometric) measurements of the skull. J Craniofac Surg 13:105-110, 2002

23. Freihofer HP: Inner intercanthal and interorbital distances. J Maxillofac Surg 8:324-326, 1980

24. Laestadius ND, Aase JM, Smith DW: Normal inner canthal and outer orbital dimensions. J Pediatr 74:465-468, 1969

25. Le TT, Farkas LG, Ngim RC, Levin LS, Forrest CR: Proportionality in Asian and North American Caucasian faces using neoclassical facial canons as criteria. Aesthetic Plast Surg 26:64-69, 2002

26. Mafee MF, Pruzansky S, Corrales MM, Phatak MG, Valvassori GE, Dobben GD, et al: CT in the evaluation of the orbit and the bony interorbital distance. AJNR Am J Neuroradiol 7:265-269, 1986

27. Méhes K, Kitzvéger E: Inner canthal and intermamillary indices in the newborn infant. J Pediatr 85:90-92, 1974

28. Milutinovic J, Zelic K, Nedeljkovic N: Evaluation of facial beauty using anthropometric proportions. ScientificWorldJournal 2014:428250, 2014

29. Nunes TP, Oliveira TF, Matayoshi S: [A comparative 
study of the manual and digital measurements of the palpebral fissure.] Arq Bras Oftalmol 68:785-787, 2005 (Portuguese)

30. Park DH, Choi WS, Yoon SH, Song CH: Anthropometry of Asian eyelids by age. Plast Reconstr Surg 121:1405-1413, 2008

31. Patil SB, Kale SM, Math M, Khare N, Sumeet J: Anthropometry of the eyelid and palpebral fissure in an Indian population. Aesthet Surg J 31:290-294, 2011

32. Prendergast PM: Facial proportions, in Shiffman MA, Erian A (eds): Advanced Surgical Facial Rejuvenation: Art and Clinical Practice. Berlin: Springer, 2012, pp 15-22

33. Richtsmeier JT, Paik CH, Elfert PC, Cole TM III, Dahlman HR: Precision, repeatability, and validation of the localization of cranial landmarks using computed tomography scans. Cleft Palate Craniofac J 32:217-227, 1995

34. Romero R: Prenatal Diagnosis of Congenital Anomalies. Norwalk, CT: Appleton \& Lange, 1988

35. Waitzman AA, Posnick JC, Armstrong DC, Pron GE: Craniofacial skeletal measurements based on computed tomography: Part I. Accuracy and reproducibility. Cleft Palate Craniofac J 29:112-117, 1992

36. Ward RE, Jamison PL, Farkas LG: Craniofacial variability index: a simple measure of normal and abnormal variation in the head and face. Am J Med Genet 80:232-240, 1998

\section{Disclosures}

The authors report no conflict of interest concerning the materials or methods used in this study or the findings specified in this paper.

\section{Author Contributions}

Conception and design: Kuang, Selden. Acquisition of data: all authors. Analysis and interpretation of data: all authors. Drafting the article: all authors. Critically revising the article: all authors. Reviewed submitted version of manuscript: all authors. Approved the final version of the manuscript on behalf of all authors: Kuang. Study supervision: Kuang.

\section{Correspondence}

Anna A. Kuang, Division of Pediatric Surgery, Department of Surgery, Oregon Health \& Science University, Mail Code: CDW7, 3181 SW Sam Jackson Park Rd., Portland, OR 97239. email: kuanga@ohsu.edu. 